\title{
Hydraulic Darrieus turbines efficiency for free fluid flow conditions versus power farms conditions
}

\author{
Sylvain Antheaume ${ }^{\mathrm{a}, *}$, Thierry Maître ${ }^{\mathrm{b}}$, Jean-Luc Achard ${ }^{\mathrm{b}}$ \\ ${ }^{a}$ Electricité de France, Recherche et Développement, Laboratoire National d'Hydraulique et Environnement, 6 Quai Watier, 78400 Chatou, France \\ ${ }^{\mathrm{b}}$ Laboratoire des Ecoulements Geophysiques et Industriels, BP 53, 38041 Grenoble, France
}

\begin{abstract}
The present study deals with the efficiency of cross flow water current turbine for free stream conditions versus power farm conditions. In the first part, a single turbine for free fluid flow conditions is considered. The simulations are carried out with a new in house code which couples a Navier-Stokes computation of the outer flow field with a description of the inner flow field around the turbine. The latter is based on experimental results of a Darrieus wind turbine in an unbounded domain. This code is applied for the description of a hydraulic turbine. In the second part, the interest of piling up several turbines on the same axis of rotation to make a tower is investigated. Not only is it profitable because only one alternator is needed but the simulations demonstrate the advantage of the tower configuration for the efficiency. The tower is then inserted into a cluster of several lined up towers which makes a barge. Simulations show that the average barge efficiency rises as the distance between towers is decreased and as the number of towers is increased within the row. Thereby, the efficiency of a single isolated turbine is greatly increased when set both into a tower and into a cluster of several towers corresponding to possible power farm arrangements.
\end{abstract}

Keywords: Cross flow water turbine; Farm modeling; Efficiency

\section{Introduction}

Exhaustion of fossil fuels resources combined with greenhouse gas negative impact have recently raised the interest for renewable energies. Among them, hydropower takes a particular place because of its huge potential. Large-hydro power plants are being built in countries such as Brazil, China or Turkey that exploit a minor part of their hydroelectric potential. Concerning countries historically well equipped, located in Europe and North America, ambitious upgrading programs are carried out to raise the extracted power of existing plants. Numerous micro-hydro power plants, presently build on rivers and canals, contribute also to the global growth of the hydropower production.

Beyond this classical exploitation, hydropower is heading toward huge ocean energy potential, especially kinetic

\footnotetext{
*Corresponding author. Tel.: + 33476825116 .

E-mail address: sylvain.antheaume@hmg.inpg.fr (S. Antheaume).
}

energy of tidal currents. Actually, harvesting the tidal current energy rather than the tidal head have lower environmental impact. Indeed, no dam is needed like in the traditional tidal power plants (France, La Rance) and the physical footprint is believed to be harmless for marine wildlife. The whole world energy potential is estimated to $2.7 \mathrm{TW}$ [1] and the exploitable part over the European shore is about $48 \mathrm{TWh}$, with 36 for UK and 10 for France. This energy could be a significant contribution to the European hydroelectric production of $580 \mathrm{TWh}$.

Within this perspective, several $R \& D$ project have been born for the past 10 years. The marine current turbine (MCT) R\&D program [2] is among the most advanced. During the first phase, Seaflow, the first commercial-scale $300 \mathrm{~kW}$ axial rotor was successfully installed in May 2003 in Lynmouth, Devon, UK. The second phase, Seagen, scheduled between 2004 and 2007 aims to design, manufacture, install and test the first "full size" twin axial rotor system to be rated at $1.2 \mathrm{MW}$. 


\section{Water current turbines technologies}

Water turbines shapes are inspired from wind turbine shapes. Most of them are driven by lift rather than by drag forces. They can be classified depending on the direction of the rotational axis relative to the water flow direction. For example, the aforementionned MCT prototype or the Hammerfest Strom marine current converter have their axis of rotation parallel to the water stream direction (i.e. horizontal, cf. Fig. 1). They are mentioned as axial flow water turbines (AFWT).

Tidal currents move back and forth. Then, the rotor orientation must be controlled. By rotating the propeller blades around their own axis at slack water when current turns, the rotor is ready for the reversing current ("pitch control") like in the Seagen prototype. Another solution is to design symmetrical propeller blades like in the Marenergy project [3] but this solution leads to lower power conversion efficiency.

Other prototypes [4-6] have their rotational axis perpendicular to the current direction (i.e. vertical, although horizontal axis can be imagined, cf. Fig. 2). They are mentioned as cross flow water turbines (CFWT) or Darrieus type water turbines (from Jean-Marie Darrieus, inventor of the first vertical axis wind turbine). A new CFWT concept has been developing within the HARVEST project assembling four laboratories of the Rhône-Alpes Région (France).

The hydraulic operation of a water turbine can be characterized by the following overall quantities: the rotor torque $Q$, the rotor drag $D$, the rotor angular velocity $\omega$ and the power output $P=\omega Q$. By dimensional analysis, these quantities can be made dimensionless as follows:

$\lambda=\omega R / V_{0} \quad$ (tip speed ratio),

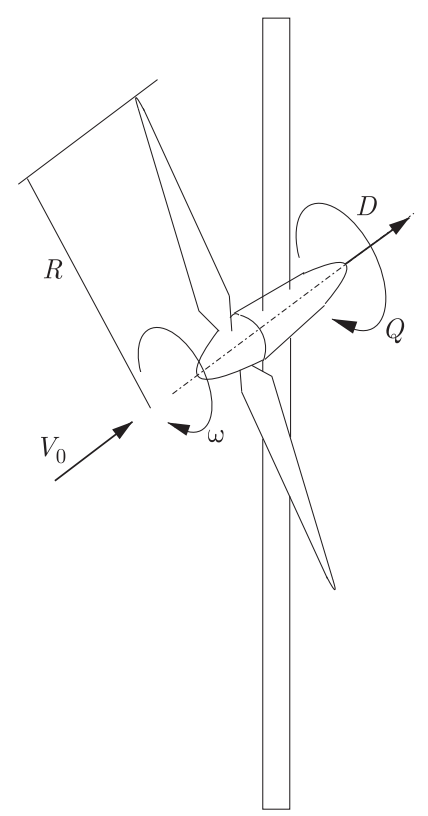

Fig. 1. Axial flow water turbine.

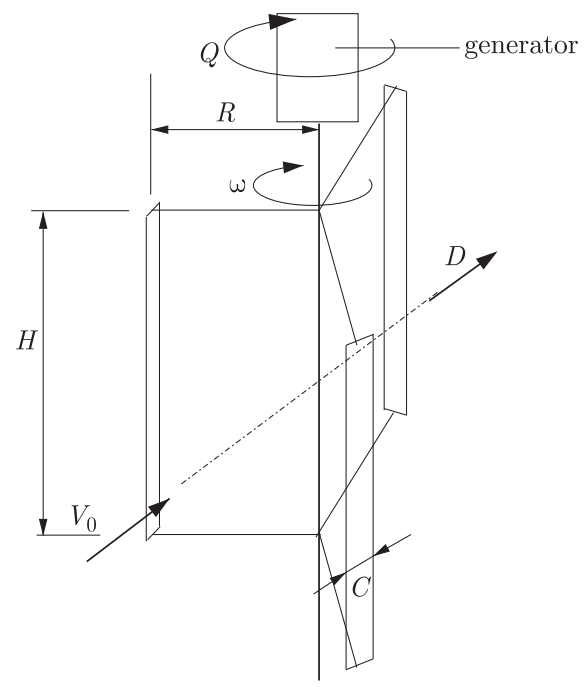

Fig. 2. Cross flow water turbine.

$C_{Q}=Q /\left(\frac{1}{2} \rho V_{0}^{2} R S_{\text {ref }}\right) \quad$ (torque coefficient),

$C_{P}=P /\left(\frac{1}{2} \rho V_{0}^{3} S_{\text {ref }}\right) \quad$ (power coefficient or efficiency),

$C_{D}=D /\left(\frac{1}{2} \rho V_{0}^{2} S_{\text {ref }}\right) \quad$ (rotor-drag coefficient),

with $R$ the maximum radius of the rotor, $U_{\text {inf }}$ the incident current velocity, $\rho$ the water specific weight and $S_{\text {ref }}$, the cross section $\left(S_{\text {ref }}=\Pi R^{2}\right.$ for AFWT and $S_{\text {ref }}=2 R H$ for CFWT). The solidity is defined as $\sigma=N C / R$ with $N$ the number of blades and $C$ the chord length.

\section{CFWT versus AFWT}

A farm concept of which the unit basis is a vertical structure, made of several piled up CFWT connected by the same rotation axis, is studied in the HARVEST project. This unit basis is defined as a tower. Only one generator or alternator is needed on top or bottom of the tower. A cluster is a gathering of several towers which can be united/ linked by their upper part with a floating or partly immersed barge. These towers can be anchored separately onto the sea bed or associated to the same cluster anchor depending on the conditions (current velocity, section depth, extracting power) and the farm environmental constraints (farm extending area, reduction of downstream velocity current, interactions with fauna and flora). These anchors which are inferior moorings can be completed with additional moorings for the barge itself. It is possible to work out a farm concept made of several clusters.

First, let us recall the obvious advantage of the CFWT: they work whatever the flow direction and are then appropriate for marine applications where the tidal flow is twice a day reversed. The advantages of CFWT specific configurations do not only limit to independence on the oncoming free stream direction. The high tip speed ratio of AFWT causes undesired cavitation. Indeed when 
cavitation occurs, the usual flow patterns at blades tip are disturbed leading both to reduced efficiency and to surface damage. Avoiding cavitation is also an imperative issue for CFWT but to a lesser extent [7].

In addition, the modular structure of relatively small parts:

(i) is well adapted for serial building and gives more options for manufacturing process;

(ii) increases the rotational speed of the turbines and then facilitate electric conversion;

(iii) is associated with a lower torque reaction that the anchors have to counteract to hold the system in place. This is true even if the global drag force resulting from the distribution of numerous CFWT modules along the vertical axis of rotation is the same as the one which corresponds to a single large AFWT module mounted on a pile. This is due to the position of the thrust center which is applied to a higher point in the later case. Consequently, a tower of CFWT modules leads to cheaper mooring per unit of energy extracted than for a large AFWT module;

(iv) allows to have flexible farm architectures. A tower is able to harvest the current energy over the whole water depth. A cluster of towers can form a kind of curtain which fits/follows the sea bed to make the most of the bathymetry. It is then possible to control accurately the impact of a farm onto the currents by working on the relative distance between towers and the relative position of clusters;

(v) is not curbed by depth limitation. For marine applications, it is estimated that $80 \%$ of the ressource is located below $40 \mathrm{~m}$, where the large AFWT can hardly be fixed on their monopile.

Moreover, the common electric converter should allow:

(i) to reduce the investment cost;

(ii) to place the gearing box (if it exists) and the electric generator up/above the barge for easier maintenance;

(iii) to have an easier maintenance of damaged turbines which can be removed along the vertical axis, using the barge facility access.

However, for air flow applications, there are three main disadvantages of CFWT versus AFWT. They are fragile because of high vibrations, they are not self-starting, and last but not least, they have lower efficiency. None of these disadvantages keeps up for water application.

To prevent the turbines from vibrating, it is possible to design the blades so that they do not lay entirely in a meridian plane, as in a classical Darrieus turbine. Thus, the cyclic hydrodynamic loading is strongly smoothed, the fatigue phenomenon is reduced and the life time of the turbine is increased. To fulfill this need, Gorlov [5] designed an helical blade shaped turbine. The Achard turbine [8] developed in the HARVEST project, uses delta blades. It can be observed that both helical and delta shapes allow self-starting of the turbines without having recourse to some extra mechanism to work properly as a Savonius device.

Concerning the third disadvantage, it is possible to improve the efficiency of a CFWT working in free fluid flow conditions, by setting the neighboring turbines interacting with it, owing to a well thought out architecture.

The key of this improvement is the limitation of the flow bypass around the turbine using a piling of CFWT (Section 7). The flow is then made bidimensional around each tower, increasing its efficiency. Furthermore, the bidimensional nature of the channelled flow between the tower gives a natural careening for the incident flow. It is then possible to optimize the tower running and thus the whole farm by acting on the tower relative arrangement within a cluster (Section 8).

As a result, a future HARVEST farm based on Achard turbines will not just be a juxtaposition of large turbines (like in the Seagen project) which occult most of the incident water depth but an optimal distribution of smallest turbines ( $1-5 \mathrm{~m}$ diameter). This distribution is actually the optimal juxtaposition of towers and possibly of clusters. Note that this optimal distribution is not satisfactory in a cluster of small AFWT for two reasons:

(i) the incident flow channeling between the turbines can not be optimal because of the facing flow circular shape of AFWT. Indeed, if one looks for an optimal distribution of several AFWT over the water depth, the space left between the turbines is not annular as it should be to make a suitable ducted flow;

(ii) several AFWT cannot share the same electric converter as it is allowed by the common vertical axis of CFWT towers.

\section{The modeling issue}

\subsection{Existing global models}

The flow field of a Darrieus type turbine type is strongly unsteady and tridimensional. This complexity is due to the dynamic stall phenomenon that a rotating blade exhibits and to the interference between shed vortices and blades [9]. Computational simulation of these complicated flow fields is an actual issue but leads to high calculation costs $[10,11]$. The chosen computational approach depends on the objective of the simulation ranging from determining detailed instantaneous blade characteristics (e.g. stall behavior), to an appraisal of the time-averaged cumulative effects of the rotating blades.

Contrary to a typical CFD approach which uses the whole set of partial derived fluid mechanics equations, the simplified models of the latter approach are based on global mass and momentum balances. They are all stationary models and can be ranged according to the 
expected approximation level. The simplest models are purely $1 \mathrm{D}$ and gives the efficiency as a function of the flow rate going through the turbine. These are called basic global models [12,13]. More complex models use a 1D approach upstream and downstream the turbine coupled with a finest description near the machine. They are more precise and give the curves of power and drag in terms of the tip speed ratio $\lambda=\omega R / V_{0}$ of the turbine. Many refinements have been proposed with time from the first single stream tube model of Templin [14]. In this original model a single tube covers the entire span of the rotor. The multiple stream tube model of Strickland [15] is worth mentioning. To cover the rotor span, an array of adjacent tubes is introduced. Paraschivoiu [16] has developed a sophisticated double-multiple stream tube model with two actuator disks placed in tandem into each tube. Note that every refinement of whatever character is limited to turbine solidities lower than 0.25 . Such solidities correspond to air flow applications and are then unappropriated for CFWT requiring higher solidities $(0.5<\sigma<1)[5,16]$.

Vortex models are intermediate between the later elaborated global models and CFD models. They need much more computational time, being of course more accurate. An interesting example is given by Ponta [17]. A new option of modeling is proposed in the present paper. It has the same elaboratness level as vortex models but is based on slightly different physical arguments. It takes advantage of the inequality $\varepsilon=C / R \ll 1$. This inequality is valid in most cases. The aim of our model is to determine the performance characteristics of a vertical axis wind or water turbine (power, drag) working alone or interacting with others in a cluster of towers. Before defining this option, let us introduce some general considerations about the cross flow turbine operation.

\subsection{Cross flow turbine operation}

The Darrieus turbine blades rotate around the vertical axis with the characteristic rotation vector $\omega$. In the $2 \mathrm{D}$ cylindric coordinates $(0, \theta, R), 0$ being the center of the turbine, the blade local relative velocity $\boldsymbol{W}$ corresponding to an undisturbed incident flow velocity $\boldsymbol{V}_{\mathbf{0}}$, is given by

$W=V_{0}-\omega \wedge R$.

When a blade rotates, its angle of attack $\alpha$, which is defined as the angle between the local relative velocity and the chord, changes leading to variable hydrodynamic forces.

$\alpha=\tan ^{-1}\left(\frac{\sin \theta}{\lambda+\cos \theta}\right)$.

Figs. 3 and 4 present, respectively, the local angle of attack and the velocity triangle at blade positions. Small tip speed ratios lead to large incidence variations during a revolution. In particular, the angle of attack becomes very large and overtakes the static stall angle of foils, about $12-15^{\circ}$.

Fig. 5 presents the normal $F_{\mathrm{n}}$ and the tangential $F_{\mathrm{t}}$ components of the hydrodynamic force on the blade. The

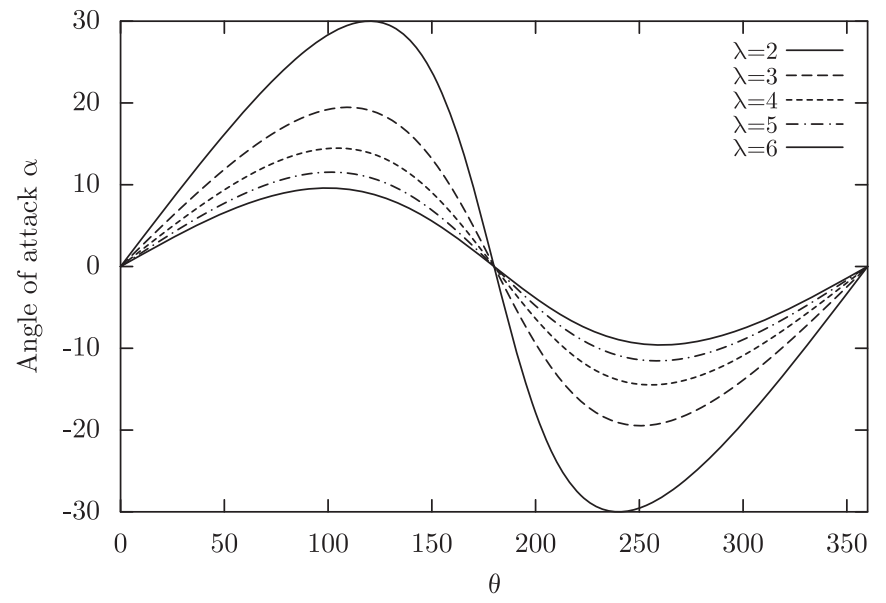

Fig. 3. Incidence at different tip speed ratio.

forces values can be inferred from classical computations over an airfoil in an unbounded domain or from available experiments in wind tunnel tests at fixed angle of attack and Reynolds number. In the upstream semi circle, with $\theta$ increasing from the $0^{\circ}$ position, the tangential force becomes positive and reaches a maximum near $\theta=90^{\circ}$ before decreasing until $\theta=180^{\circ}$. One can observe the same behavior in the downstream semicircle between the $\theta=$ $180^{\circ}$ and $360^{\circ}$ positions. It is this positive tangential component which is responsible for the rotation of the turbine. In the vicinity of the $\theta=0^{\circ}$ and $180^{\circ}$ positions, the blade has a negative tangential component force $F_{\mathrm{t}}$, opposed to the rotational motion.

Reals flows around blades in CFWT may indeed differ from these conclusions because of the two following points:

(i) the relative flow passing through a CFWT blade is unsteady;

(ii) the oncoming far field seen by a blade is not $\boldsymbol{V}_{\mathbf{0}}$, the upstream absolute velocity, but some unspecified velocity.

The first point is obvious and the second point which is more important deserves some comments. When the crossflow runner works at a given tip speed ratio, a macroscopic flow pattern develops and stabilizes over the space scale $R$ that we shall assume much greater than the chord length $C$. In addition there should not be too many airfoils to guarantee that $C$ is small compared to the distance between the airfoils. In this usual situation, the space and time variables far from the blades can be made dimensionless using $R$ and $R / V_{0}$. By the way, mention that the precise shape of this pattern has been discussed in literature. For instance, the 1D Betz theory, which claims to give an upper limit of the performance of wind turbine of whatever type, assumes an expanding flux tube. In this model the effective area of the incoming free flow (which does interact with turbine) is smaller than the swept area while the distance between the limiting interacting flux lines is larger than the turbine diameter dimensions far away from the turbine. On 


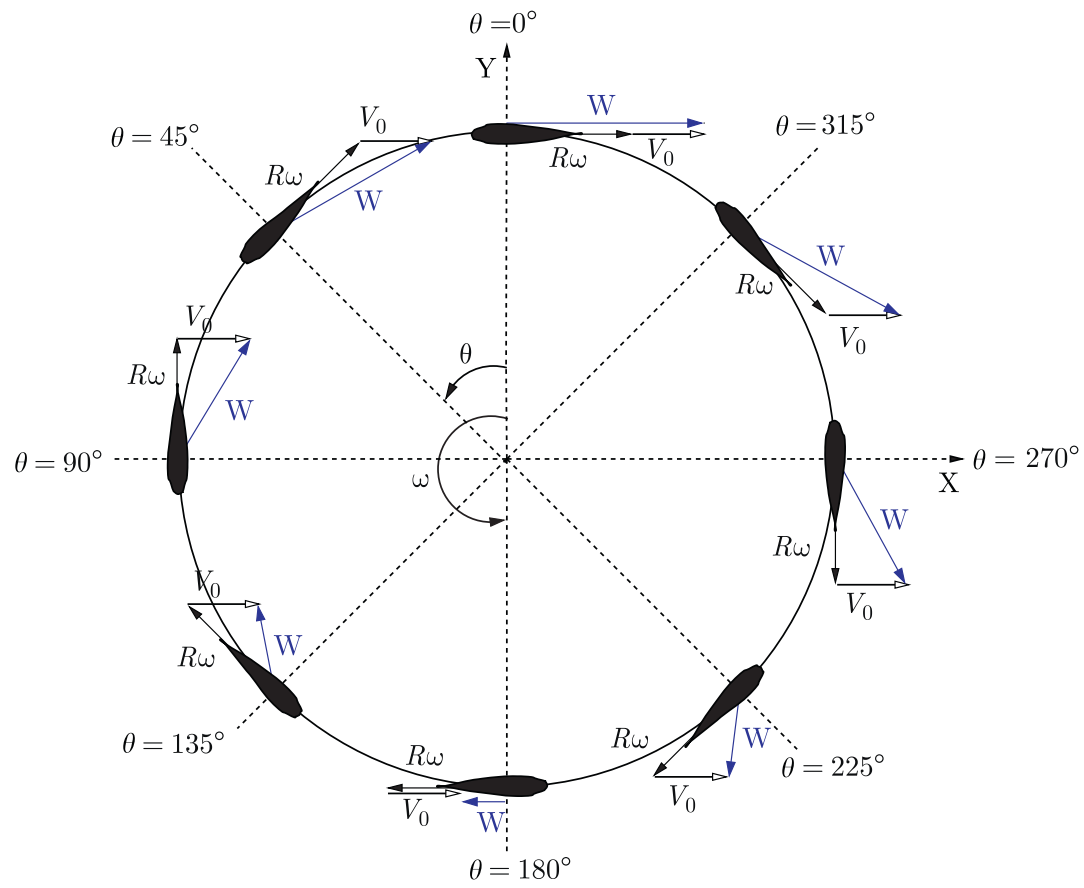

Fig. 4. Velocity triangle.

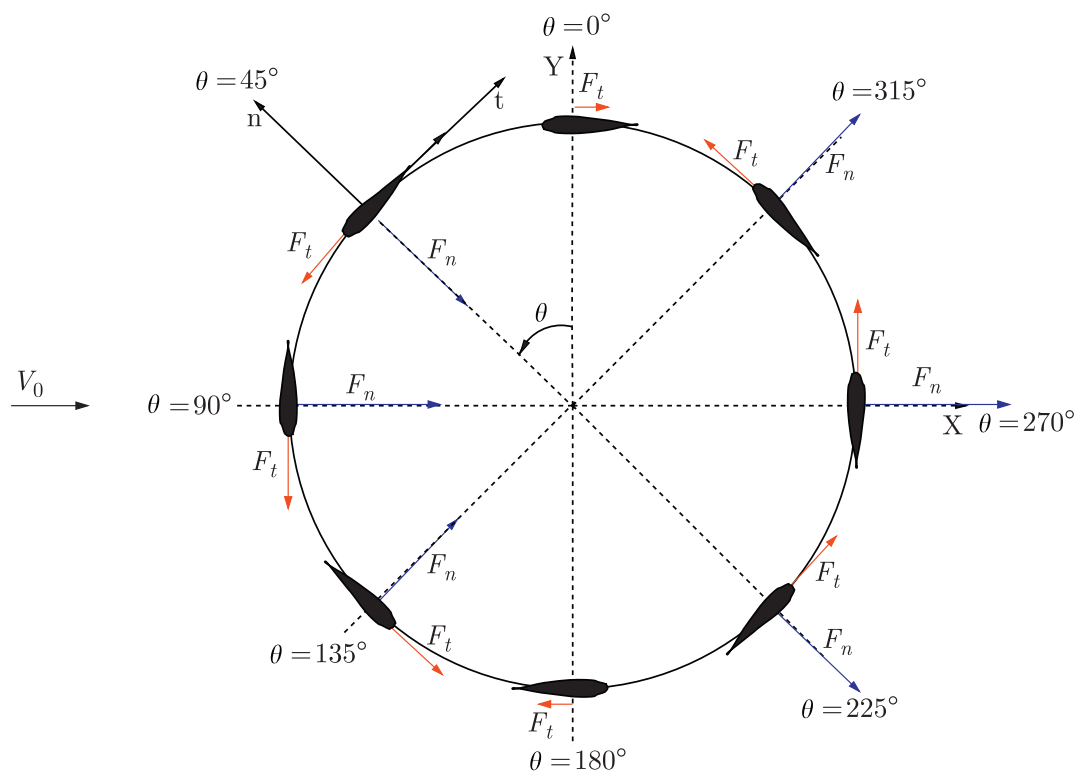

Fig. 5. Normal and tangential forces.

the other hand, Agren et al. [7] show that in their model, the effective area may be greater than the swept area... . In any case, the far field incoming flow that each blade at given angular position observes with the space and time scales $C$ and $C / V_{0}$, proper to microscopic equations, is not the undisturbed incoming velocity $\boldsymbol{V}_{\mathbf{0}}$ but a distorted one, given by the macroscopic equations.

These considerations suggest a solution approach, classical in computational fluid dynamics, based on various asymptotic expansions in terms of $\varepsilon=C / R$ which differ according unknowns are near (inner region) or far (outer region) from the blades. In our case, the order of the system proper to the macroscopic outer region does not change in the limit of vanishing $\varepsilon$. Viewed from the macroscopic region, the inner regions around blades degenerate to points centered on blades. Expansions valid near these singularities have to be matched with expansions valid far away.

As a matter of fact the approach presented in the following will be restricted to matching the leading-order terms of each expansions. Moreover all the formal aspects of the above asymptotic methods will be excluded. A more simple and intuitive modeling will be used. Similar straightforward approaches can be found in the literature. 
For instance we may mention Takamatsu et al. [18] who has studied, in the area of the vortex method, the hydrodynamic performance of cross-flow water turbines placed in a channel. The technique is also similar to the one developed by Zori et al. [19] for simulating an helicopter rotor system: the effect of the turbine on the flow field is modeled through source terms in the momentum equations placed in a volume swept by the rotating blades. Pointing out the asymptotic foundations of such approaches is not useless especially for future studies. First it should furnish a rigorous procedure for obtaining the next $\varepsilon$ order microscopic and macroscopic equations permitting to improve results. More importantly, it gives a rational way to incorporate transient effects which are disregarded in these approaches as well in ours.

\section{Method of solution}

Following the above lines a new CFD-macroscopic coupled code has been developed. The macroscopic flow field is solved with the commercial code Fluent using a $k-\varepsilon$ turbulence model and a steady state formulation. The turbine perturbation of the incoming free flow is modeled, within the turbine swept volume, with a volume force introduced in the right hand side of the momentum equation. This source term corresponds to the aforementioned inner or microscopic part of the solution. It can be obtained in two ways, either from experimental data or by solving the inner problem which corresponds to computing the solution around an airfoil in an unbounded domain.

In the present method, the blade source terms are evaluated using the blade element theory, requiring the aerodynamic coefficients of the blades. For a straight Darrieus turbine, the swept volume is an annular cylinder of blade thickness, centered on the turbine axis of rotation. It is meshed with $N_{\text {Cell }}$ structured annular cells of $\Delta \theta$ angular size and $\Delta Z$ axial size (Fig. 6). The mesh is uniform along the $\theta$ direction and is refined in the $Z$ direction at the tip of the turbine.

Let us consider a cell in the swept volume and suppose that a guess of the flow field is known (for example an arbitrary initialization of the flow needed by a RANS solver). Then it is possible to compute, at the center of the cell, the local relative velocity $\boldsymbol{W}$ and the local angle of attack $\alpha$ between $\boldsymbol{W}$ and the chord. The instantaneous lift and drag force applied on the part $\Delta Z$ of the blade span centered on the considered cell is given by

$F_{L, D}=C_{L, D}\left(\alpha, R e_{\mathrm{c}}\right) C \Delta z \frac{\rho W^{2}}{2}$,

where $C_{L}$ and $C_{D}$ are, respectively, the static lift and drag coefficients of the blade section and $R e_{\mathrm{c}}=R \omega C / v$ is the chord Reynolds number.

The force applied on the flow by the blade element can be easily expressed in the fixed system coordinate $(O, X, Y)$ by projection of $-F_{L}$ and $-F_{D}$ on the $X$ and $Y$ axes (the minus sign coming from the action/reaction principle). The

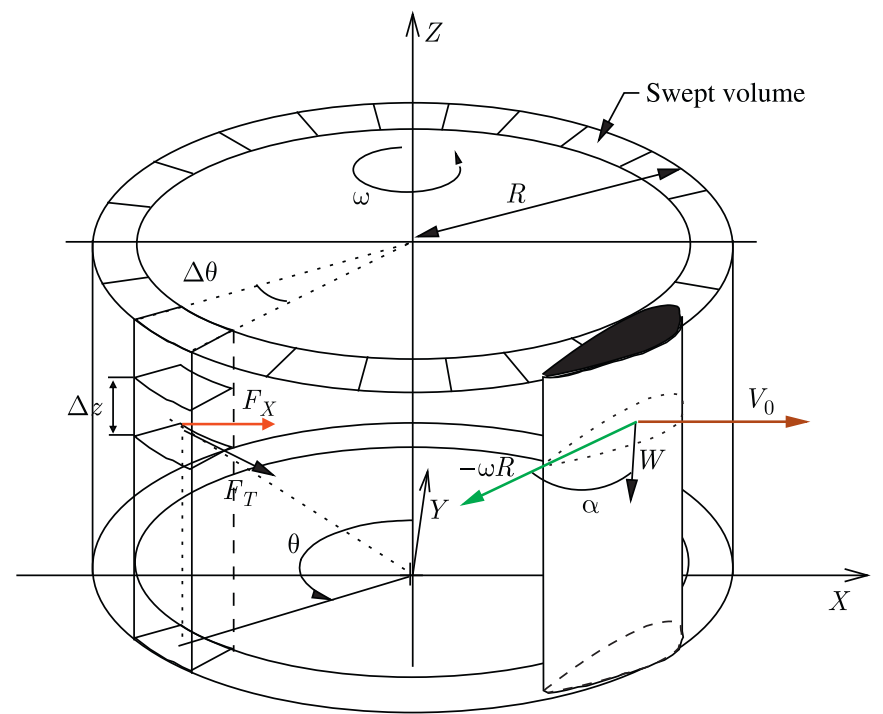

Fig. 6. Schematic view of the discretized swept volume.

obtained components, $F_{X}$ and $F_{Y}$, cannot be directly introduced as source terms because they are instantaneous and consequently not consistent with the expected steady state solution. Actually, the correct terms correspond to the mean time value of $F_{X}$ and $F_{Y}$ on a period of revolution. Assuming a constant rotational speed of the turbine and considering that the hydrodynamic forces are:

(i) constant when the quarter chord blade point is in the cell;

(ii) 0 when it is out.

The time averaging operation leads simply to a multiplicative factor $N \Delta \theta / 2 \Pi$ for a $N$ bladed turbine. As a result, the corresponding average values $F_{X_{\text {Cell }}}$ and $F_{Y_{\text {Cell }}}$ of $F_{X}$ and $F_{Y}$ are the following:

$F_{X, Y_{\text {Cell }}}=F_{X, Y} N \Delta \theta / 2 \Pi$.

For each cell lying in the swept area, $F_{X_{\text {Cell }}}$ and $F_{Y_{\text {Cell }}}$ are divided by the cell volume before being introduced in the $X$ and $Y$ momentum equations. This operation is done at every iteration of the solver until the turbine efficiency (or drag) stabilized. A relative precision of $10^{-3}$ is required.

Every iteration, several coefficients of interest are calculated as

(i) the turbine drag coefficient:

$$
C_{D}=\frac{\sum_{i=1}^{N_{\text {Cell }}} F_{X_{\text {Cell }}}}{1 / 2 \rho S_{\text {ref }} V_{0}^{2}}
$$

(ii) the turbine lift coefficient:

$$
C_{L}=\frac{\sum_{i=1}^{N_{\text {Cell }}} F_{Y_{\text {Cell }}}}{1 / 2 \rho S_{\text {ref }} V_{0}^{2}}
$$


(iii) the turbine power coefficient:

$$
C_{P}=\frac{\omega R \sum_{i=1}^{N_{\text {Cell }}} F_{T_{\text {Cell }}}}{1 / 2 \rho S_{\text {ref }} V_{0}^{3}},
$$

where $F_{T_{\text {Cell }}}$ is equivalent of $F_{X_{\text {Cell }}}$ and $F_{Y_{\text {Cell }}}$ for the tangential component.

The following sections present results obtained with the Fluent solver. The above calculations are performed using the user defined functions. In all the test cases, the Fluent solver parameters are listed below:

(1) segregated solver;

(2) pressure-velocity coupling: simple;

(3) standard discretization for pressure; first order upwind for momentum, turbulence kinetic energy, turbulence dissipation rate;

(4) standard $k-\varepsilon$ turbulence model.

The boundary conditions used for the domain are:

(1) velocity inlet condition at the upstream boundary;

(2) pressure outlet condition for the downstream boundary;

(3) walls with zero shear stress for others domain frontiers;

(4) symmetry condition at the meridian plane to minimize computational effort when running 3D simulations.

Fig. 7 shows an upper view of the straight Darrieus turbine grid, in the $X-Y$ plane (valid in 2D and 3D) and Fig. 8 presents a zoom of the turbine area. The grid density depends directly on the $\Delta \theta$ size of the cells describing the annular swept area (in dark in Fig. 8). A grid sensitivity study, performed in $2 \mathrm{D}$, has shown that $\Delta \theta=4.5^{\circ}$ ( 80 cells) was sufficient to stabilized the results. A typical 3D mesh of a straight Darrieus turbine is presented in Fig. 10. The turbine diameter is twice the height because of the symmetry condition at the bottom plane. The $3 \mathrm{D}$ mesh is obtained by sweeping the $2 \mathrm{D}$ one along the $Z$ axis. The used $Z$ discretization is the result of a sensitivity study. It leads to the following rules:

(1) at the symmetry plane, the $\Delta Z$ size is equal to $R \Delta \theta$;

(2) at the turbine or tower tip, the $\Delta Z$ size is equal to the blade thickness;

(3) the $\Delta Z$ size is increased from the turbine or tower tip to the top of the flow domain;

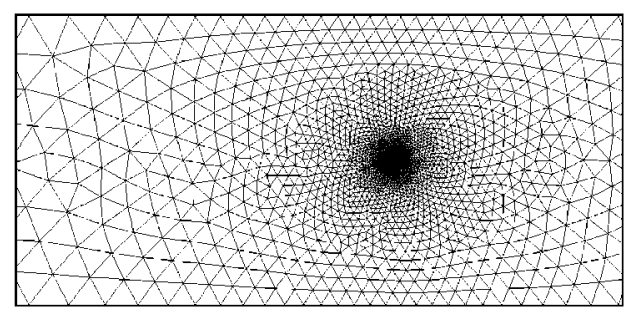

Fig. 7. $2 \mathrm{D}$ grid.

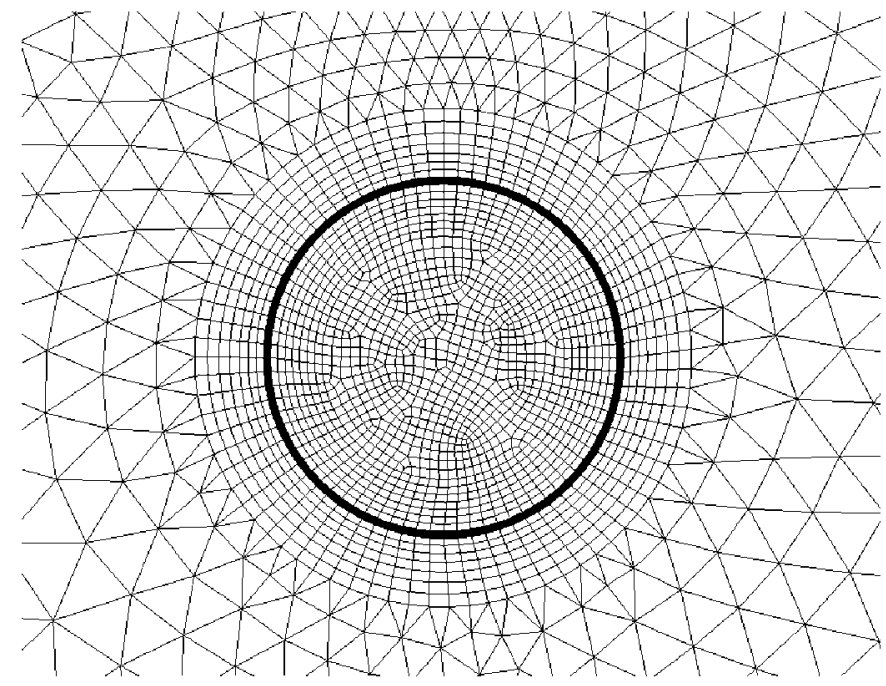

Fig. 8. Zoom of the turbine area.

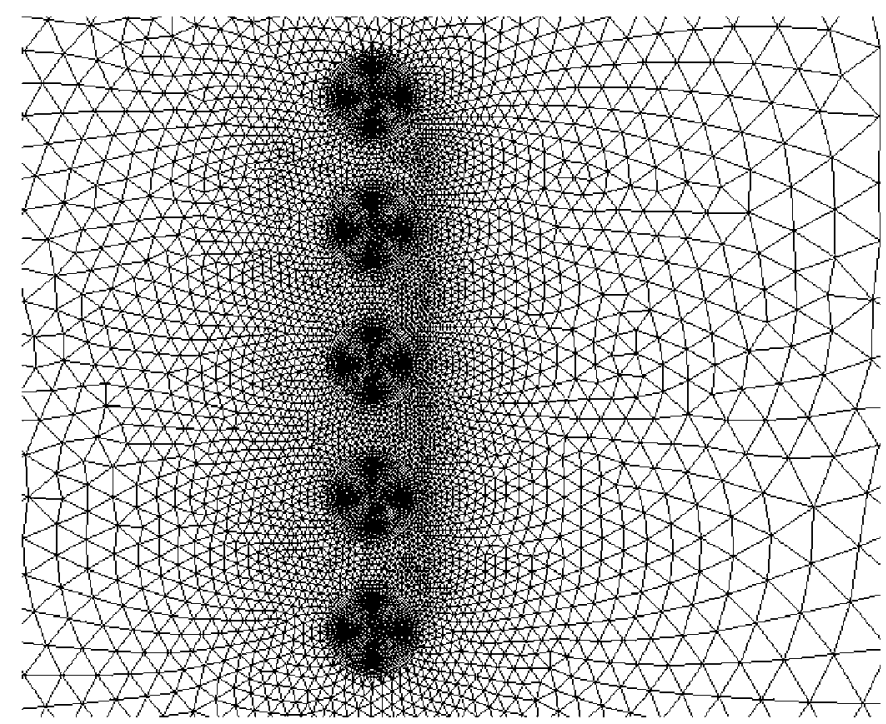

Fig. 9. Zoom of a barge grid.

(4) the $\Delta Z$ ratio from the tower tip to the upper boundary is 1.1 .

Notice that the above $2 \mathrm{D}$ and $3 \mathrm{D}$ grid specifications correspond to 2D and 3D calculations of straight Darrieus turbines, towers and barges presented, respectively, in Sections 6.2, 7 and 8. For 2D cases, the free stream conditions are obtained with a domain width equal to 40 times the turbine diameters (Section 6.2) or barge width (Section 8). For 3D cases, the free stream conditions are obtained with a domain height equal to 40 times the turbine or tower height (Section 7). Therefore, the blockage ratio equals $1 / 40$ in the transverse and vertical (3D cases only) directions for each tested configurations. There is no domain boundary influence on the results but only the effect of specific CFWT layouts. Fig. 9 shows a zoom of the barge grid in the case of a two diameter spacing between 
turbines. Fig. 10 shows the surface grid of an isolated 3D straight turbine.

For the 3D parabolic turbine, Section 6.1, the 2D grid of the symmetry plane and the $3 \mathrm{D}$ grid of the turbine volume follow the grid specifications (cf. Fig. 12). The 3D grid of the volume exterior to the turbine is tetrahedral and based on the surface grids.

\section{Single CFWT: evaluation of the code, comparison with experiment}

\subsection{The Sandia wind turbine experiment}

Darrieus turbines were initially developed for wind power generation. The SANDIA laboratories run intensive experiments for many wind turbine configurations and blade profiles and provide a rich database of experimental results. To evaluate the present method, three blade configurations of $2 \mathrm{~m}$ diameter Darrieus wind turbine with NACA-0012 airfoils are chosen [20]. The geometrical difference between the three configurations is the solidity of the turbines. A summary of the experimental test conditions is given in Table 1. Measurements have been carried out in the Vought Corporation low speed wind tunnel (Fig. 11). For each configuration, the turbines were operated at constant rotational speed. The wind velocity was adjusted to obtain the desired value of tip speed ratio. The steady state turbine torque was measured to determine the power coefficient. Because the chord Reynolds number

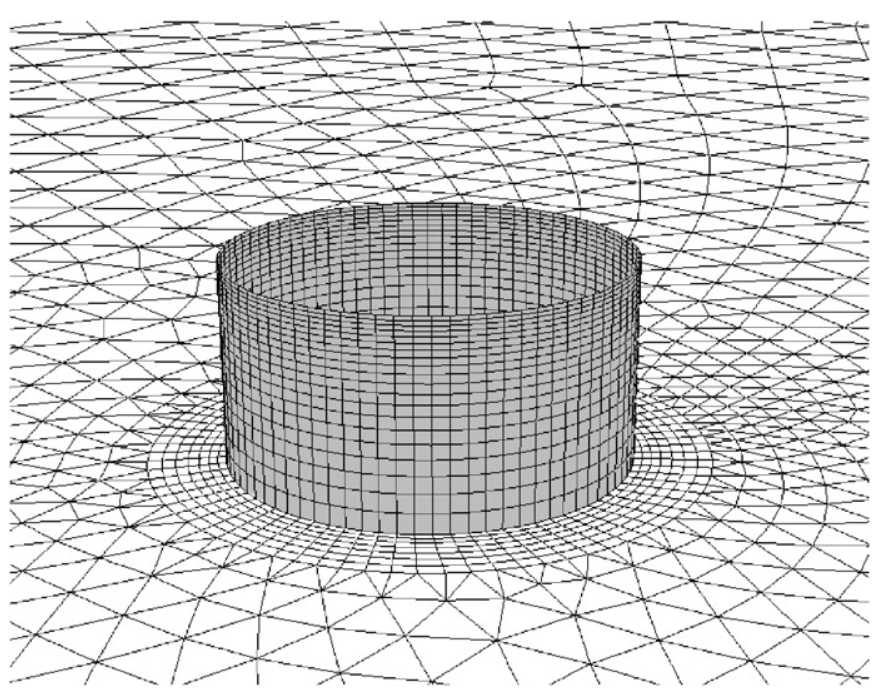

Fig. 10. Surface grid of an isolated 3D turbine.
$R e_{\mathrm{c}}$ does not change within the whole range of tested tip speed ratio $\lambda$, only one data set of hydrodynamic coefficients $C_{L}, C_{D}$ for a given $R e_{\mathrm{c}}$ of about 150000 is used to run the simulations.

Calculations are run in water using the geometrical dimensions of the wind tunnel and of the turbine. To fulfill the similarity conditions, the chord Reynolds number $R e_{\mathrm{c}}$ and the tip speed ratio $\lambda$ are kept equal. These conditions give the rotational velocity and the upstream velocity for the simulation.

The NACA-0012 hydrodynamic coefficients are obtained from SANDIA experimental data [21]. The zero drag coefficient $C_{D_{0}}$ corresponding to a 0 angle of attack is corrected to take into account the additional drag due to other rotating parts of the turbine. This additional drag is obtained by spinning the rotor in still air (see Fig. 12). The same method is used in [16].

Fig. 13 shows a good agreement between experimental and calculated power coefficients, especially in the ranges of $\lambda$ above the value corresponding to the maximum $C_{P}$. In these regions the flow is dominated by the so called "secondary effects" corresponding to a viscous attached flow. The good quality of the comparison is mainly due to adjusting the $C_{D_{0}}$ value. In the range of $\lambda$ below the maximum $C_{P}$, a significant difference is observed between calculated and experimental $C_{P}$. This gap is mainly due to the dynamic stall phenomenon (called "primary effects") that a rotating blade exhibits. The associated complex

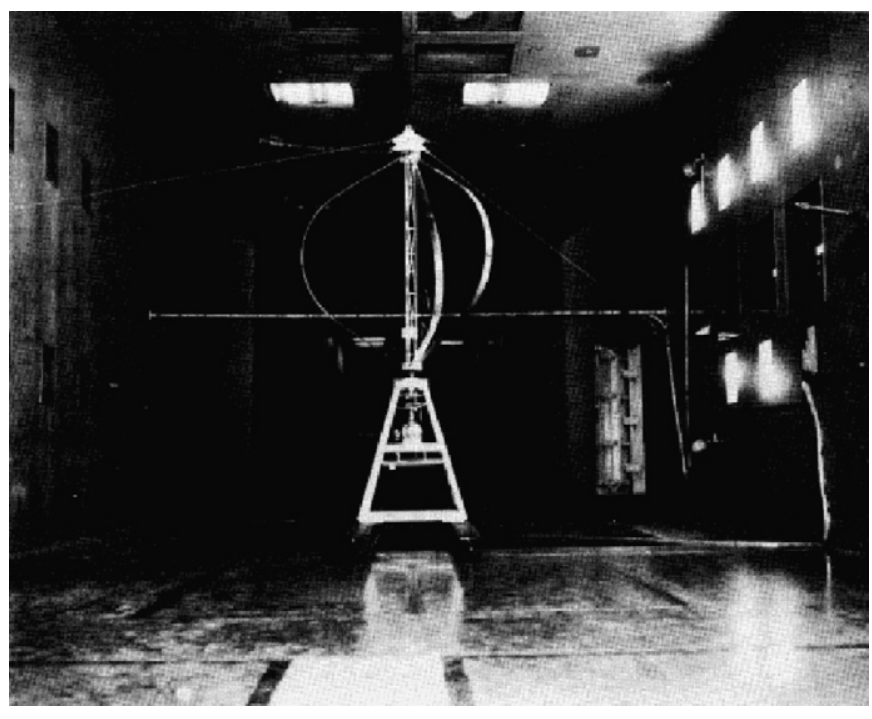

Fig. 11. Vought corporation low speed wind tunnel.

Table 1

Experimental test configurations

\begin{tabular}{llllll}
\hline Config number & Number of blades & Solidity (\%) & Rotor speed (rpm) & Chord (cm) & Chord Reynolds number \\
\hline 1 & 3 & 24.45 & 267 & 8.815 & 150000 \\
2 & 3 & 22 & 320 & 7.346 & 151000 \\
3 & 3 & 17.63 & 400 & 5.877 & 154000 \\
\hline
\end{tabular}




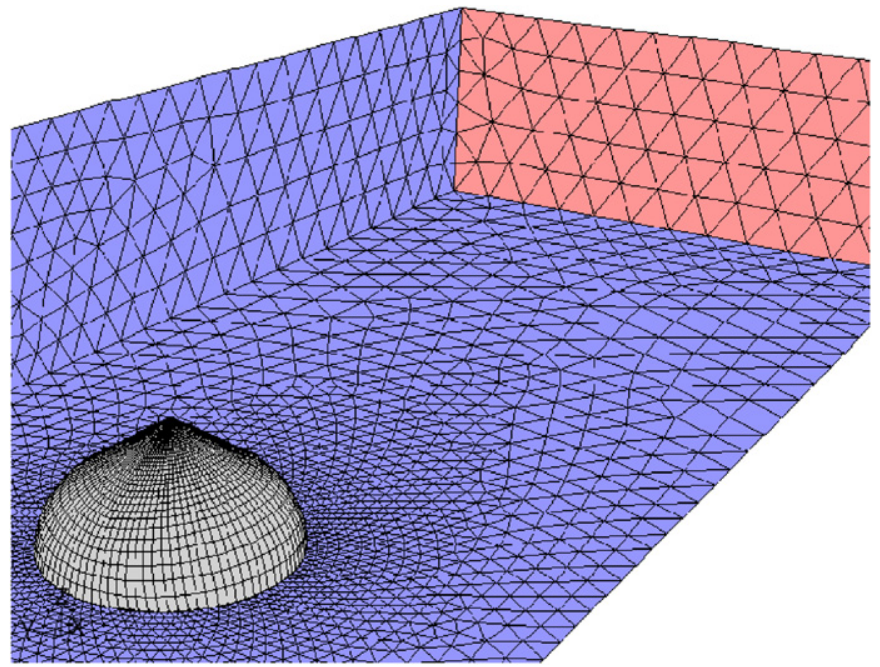

Fig. 12. Mesh of half the flow domain.

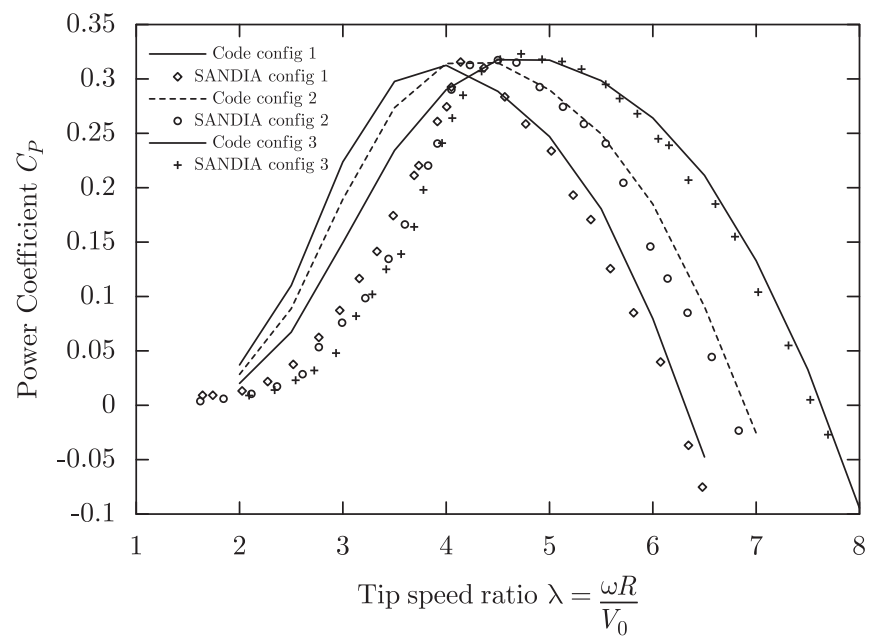

Fig. 13. Comparison between SANDIA experiment and code, $R e_{\mathrm{c}}=$ 150000 .

interactions between blades and shed vortices lead to strong unsteady effects revealed by an hysteresis loop for the blade loading [22]. Though the dynamic stall phenomenon can be taken into account by some semi empirical corrections [23] it has not been done in this study for two reasons. First of all, the influence of these corrections on the mean power and drag coefficients are of second order for nominal tip speed ratios which corresponds to moderately stalled regime. Secondly, they are not directly linked with the objective of the present study which focuses on the limitation of the by-pass effect around a CFWT when inserted in a column or a cluster of columns.

\subsection{Straight Darrieus hydraulic turbine for free stream conditions}

The present numerical model has been tested in the cases of three parabolic Darrieus wind turbines. For large dimensions, these turbines can reach an efficiency up to
0.45 , a little bit less than modern axial flow turbines. These performances are obtained with moderate solidity [0.15-0.25] for a tip speed ratio about 5-6. As mentioned above, the future power farm studied in the HARVEST project is based on turbines equipped with delta wings. These turbines are expected to be more efficient than classical straight blade Darrieus turbine (23\%) [24] thanks to a reduction of the tip vortex induced drag. Other water turbines have already attained a better efficiency. For example Gorlov obtained 35\% with its helical turbine in the Cap Cod Canal [5] and a similar turbine tested in the open jet tunnel of TU Delft exhibited 29\% [25], confirming the interest of the helical shape. Faure [26] obtained good efficiencies on straight blade Darrieus turbines (more than $40 \%$ ) but the experiments where purely $2 \mathrm{D}$, leading probably to a smaller influence of tip vortices. Generally, it is observed that an increase of performance produces an increase of tip speed ratio at maximum efficiency leading the designer to shape turbines with smaller solidity.

To highlight the favorable impact on efficiency obtained by a CFWT tower, a typical HARVEST CFWT is chosen. The diameter and height are both set to $1 \mathrm{~m}$, the solidity is set to 0.6 and the upstream velocity $V_{0}$ is set to $3 \mathrm{~m} / \mathrm{s}$. The diameter based Reynolds number $R e_{\mathrm{D}}=R \omega C / v$ is equal to $3 \times 10^{6}$. The maximum efficiency of this turbine, operating alone at free fluid flow conditions, is set to $29 \%$, corresponding to an average between the worst $(23 \%)$ and the best $(35 \%)$ efficiency of similar CFWT. Notice that this choice is not so important, arguing the fact that the aforementioned involved issues do not depend (at least qualitatively) on the exact performance of the turbine. Calculations are performed with the $3 \mathrm{D}$ code using the same data set as in Section 6.1. The only difference concerns the zero drag coefficient $C_{D_{0}}$ adjusted to fit the required $29 \%$ maximum efficiency. Figs. 14 and 15 present, respectively, for the maximum efficiency operating point $(\lambda=2.5)$, the pressure coefficient $C_{P}=\left(P-P_{0}\right) /\left(0.5 \rho V_{0}^{2}\right)$ and the reduced $X$ velocity $V_{X} / V_{0}$ on the turbine surface

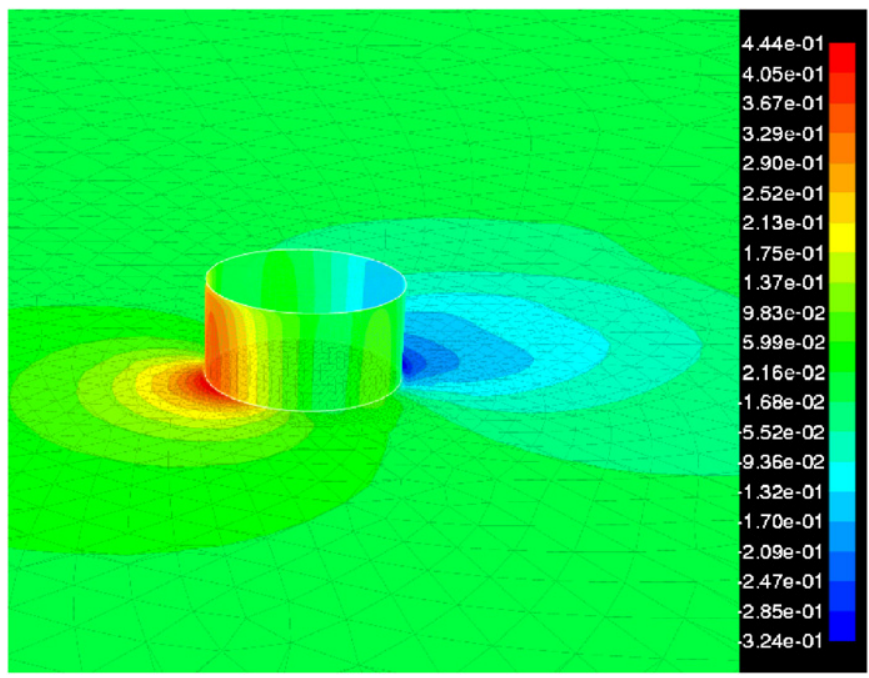

Fig. 14. Pressure coefficient, $\lambda=2.5$. 
and on the symmetry plane. Because there is no stagnation point, the maximum pressure coefficient is equal to 0.44 . Contrary to the pressure, the velocity is affected in a wake extending very far downstream from the turbine. No reverse flow is observed in the wake. Fig. 16 shows for a higher tip speed ratio $\left(\lambda=3.5\right.$ and $\left.C_{P}=0\right)$ several streaklines starting from upstream positions. These streaklines are colored with the reduced $X$ velocity. This figure shows the bypass effect around the turbine and a reverse flow region, highlighted by a large recirculating zone situated one diameter downstream of the turbine.

To compare the efficiency of the isolated turbine with a purely $2 \mathrm{D}$ isolated tower based on the same turbine,
2D calculations are also performed. In this case, two higher solidities 0.8 and 1 have been also considered. Fig. 17 presents the power coefficient against the tip speed ratio for the three $2 \mathrm{D}$ isolated towers and for the $3 \mathrm{D}$ isolated turbine. One can observe first that the code is able to simulate high solidities contrary to the existing global models (Section 4). Then, it accurately represents the effect of changing blade solidity (i.e. with increased solidity, the maximum power coefficient and the optimal tip speed ratio decreases). Finally, results show that the maximum efficiency of the purely $2 \mathrm{D}$ isolated CFWT tower is $34.85 \%, 5.85 \%$ more than the $3 \mathrm{D}$ isolated CFWT.

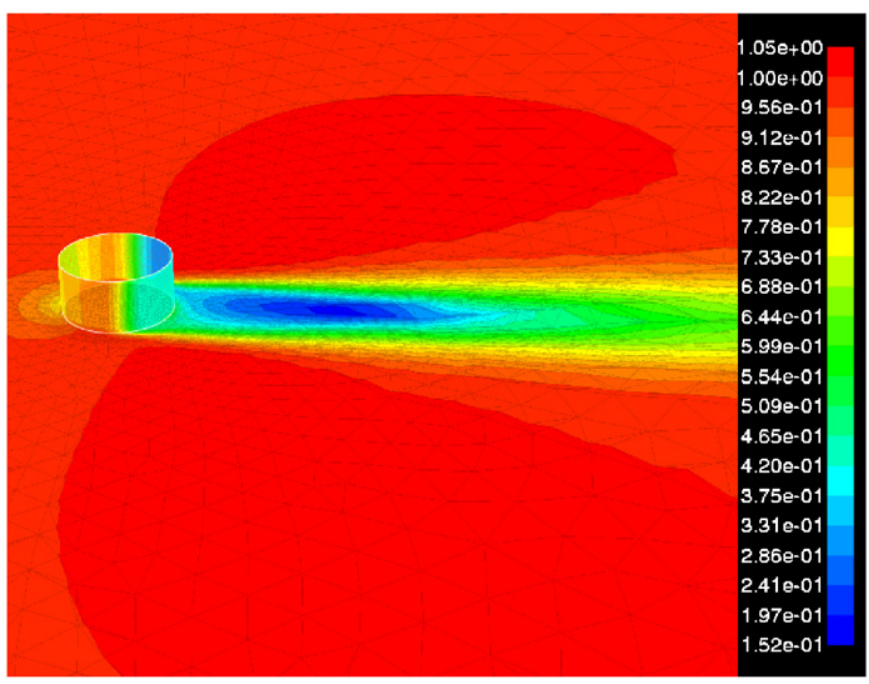

Fig. 15. Reduced $X$ velocity $V_{X} / V_{0}, \lambda=2.5$.

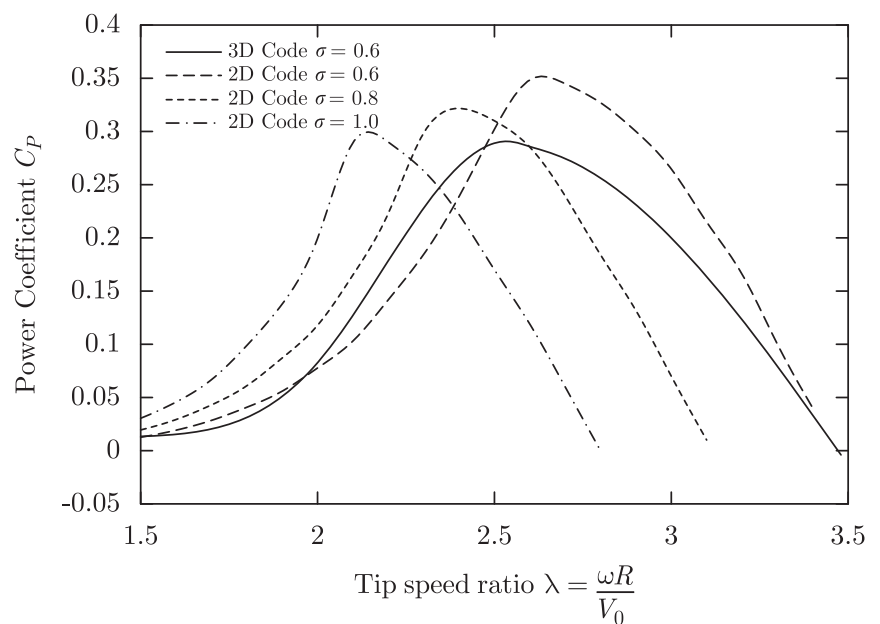

Fig. 17. Power coefficient for three $2 \mathrm{D}$ and one $3 \mathrm{D}$ hydraulic turbines simulations, $R e_{\mathrm{D}}=3 \times 10^{6}$.

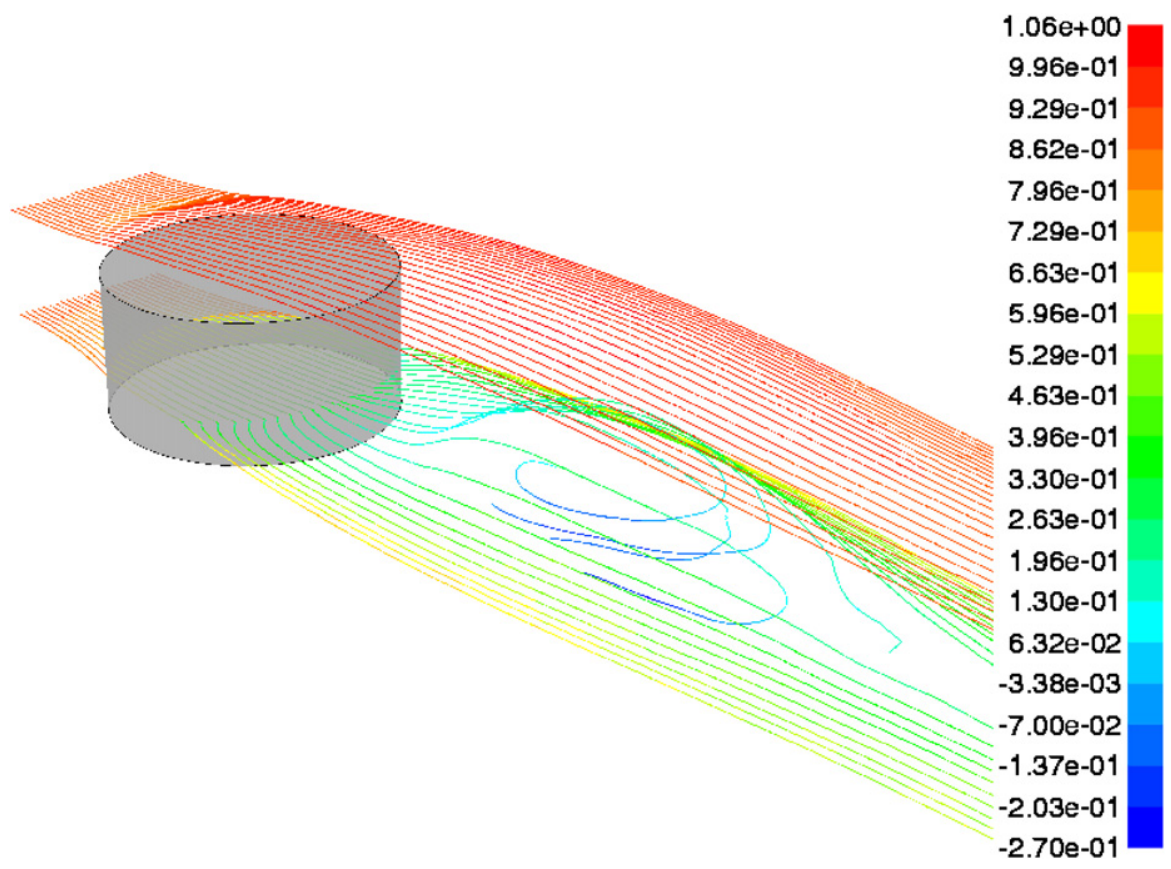

Fig. 16. Streaklines colored with the reduced $X$ velocity, $\lambda=3.5$. 


\section{The tower configuration}

When the fluid faces the turbine body, it tends to get around toward the less resisting areas. This phenomenon is responsible for a potential decrease of efficiency. There are two means to prevent this. First, one can design channeling devices to force the flow to go through the turbine $[3,4,27]$. Likewise, cross flow water turbine performance tests showed that the best efficiency is obtained under the narrowest channel height condition [18]. The second solution is to work on the shape of the turbine and/or on the assembly of several turbines so that the bypass effect is limited. As said before in Section 3, the CFWT technology allows to pile turbines to shape towers. We have already pointed out a difference of almost $6 \%$ in efficiency between the single isolated turbine and a purely $2 \mathrm{D}$ tower. Nevertheless, an important question is open concerning this positive 2D effect: how many elementary turbines is needed in a 3D tower to obtain a significant increase of its efficiency? To answer the question, 3D simulations of towers built with different number of turbines of 0.6 solidity are performed. Table 2 gives that $33 \%$ is obtained for a eight turbine tower, three points above the 3D turbine. This increase corresponds to $62 \%$ of the maximum obtained in the purely $2 \mathrm{D}$ case.

Fig. 18 shows the pressure coefficient at $\lambda=2.6$ on the eight turbine tower surface and on the symmetry plane. It can be seen that only the last turbine at the tower tip is affected by $3 \mathrm{D}$ effects. This explains why the tower efficiency increases with the number of turbines.

Table 2

Maximum efficiency for different tower configurations

\begin{tabular}{lllll}
\hline Number of turbines & $1(3 \mathrm{D})$ & 4 & 8 & $2 \mathrm{D}$ \\
Maximum $C_{P}(\%)$ & 29 & 32.05 & 33.02 & 34.85 \\
\hline
\end{tabular}

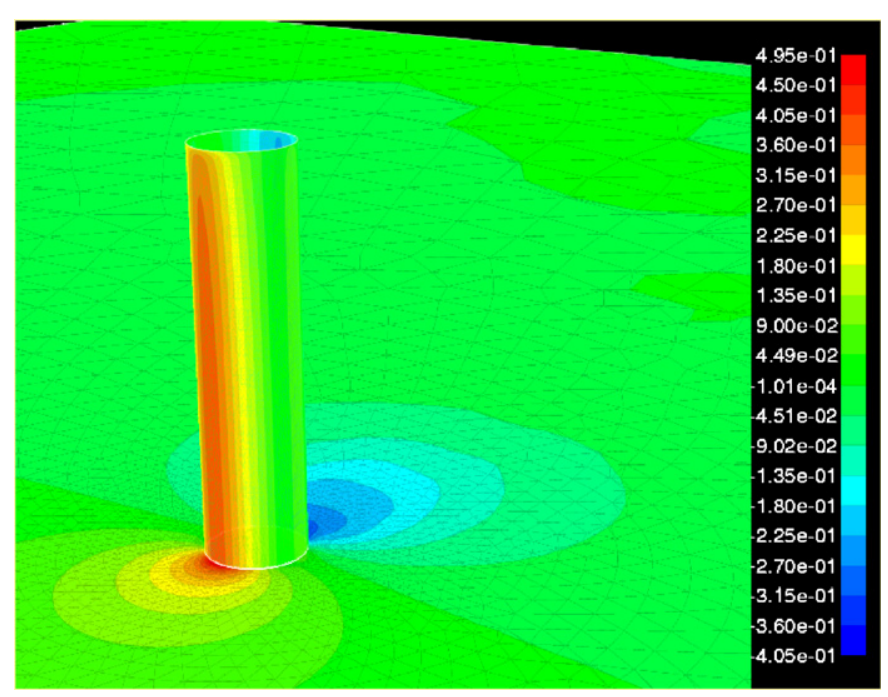

Fig. 18. Pressure coefficient for the eight turbine tower, $\lambda=2.6$.

\section{The barge configuration}

The towers can be aligned within a cluster which represents a potential barge. The objective of this section is to investigate the influence of the tower spacing and the number of towers on the average efficiency of a cluster (i.e. the sum of each tower power coefficient divided by the number of towers within the barge). To simplify the analysis, purely 2D towers of Section 6.2 are considered. The chosen solidity is 0.6 and all CFWT operate at the same rotational speed corresponding to the optimal $\lambda=$ 2.65 for an isolated configuration. The corresponding maximum efficiency is $34.85 \%$ (Fig. 17).

The first test consists in moving closer five towers to investigate the effect of tower spacing on the maximum average efficiency. One can notice in Fig. 19 than the closer the barges, the better the efficiency. Once again, this result can be explained by the velocity streamlines straightening effect of the configuration (Fig. 20). For a lateral spacing of 1.5 turbine diameter, the maximum average efficiency reaches $39.32 \%, 4.5 \%$ more than for the single isolated tower. However, we have to be cautious regarding the feasibility of such a close up barge. For instance, we can expect that it would be prohibited to prevent the towers from knocking with each other or to let enough space for the aquatic fauna.

The second test consists in setting the space between towers to a specified value and see how the average efficiency evolves when adding new towers in the row. For this numerical experiment a reasonable lateral spacing of two turbine diameter is chosen. Fig. 21 presents the average efficiency of the barge as a function of the number of towers. We clearly see that adding new towers in the row raises the barge efficiency. It tends to stabilize around $43 \%$. It is also interesting to observe that more than $40.5 \%$ is reached for a 10 tower cluster. Finally, comparing with the $29 \%$ efficiency of the initial 3D isolated turbine, $11.5 \%$ efficiency improvement is obtained.

Obviously, flow conditions around each turbine are not similar and thus, running every turbine in the row at the same rotational speed is not optimal to obtain the best

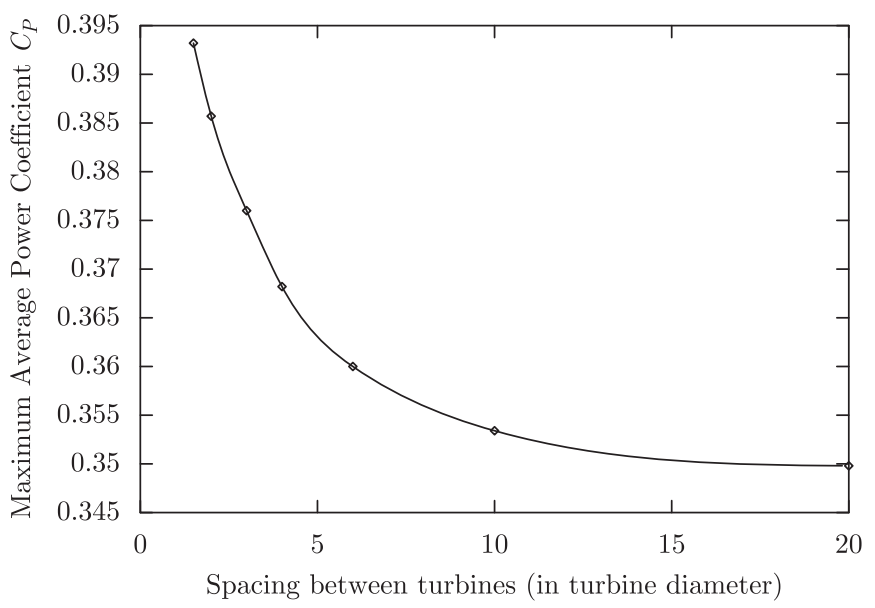

Fig. 19. Spacing turbine effect on performance. 


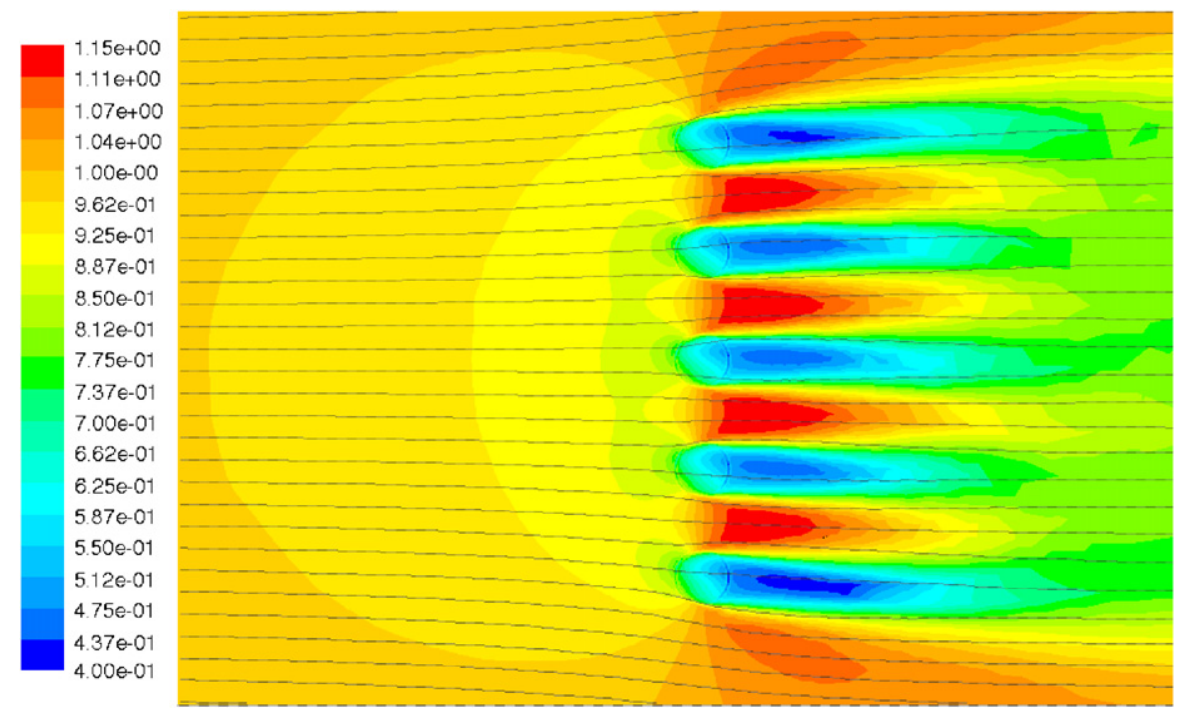

Fig. 20. Velocity streamlines in the barge region colored with the reduced velocity $V_{X} / V_{0}$, two turbines diameter spacing between turbines.

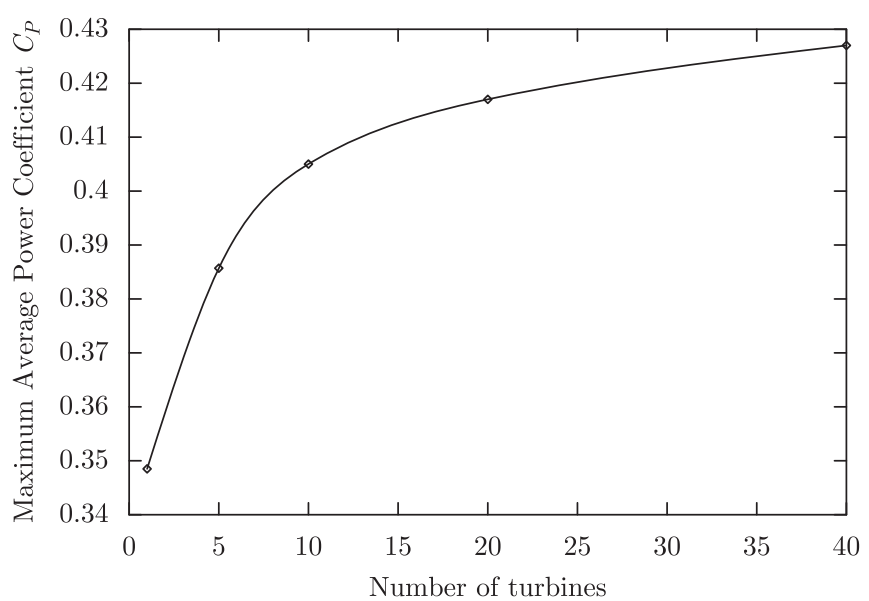

Fig. 21. Turbine number effect on performance.

efficiency. For instance, it would be profitable in a future study to adjust the rotational speed of each turbine with the individual upstream velocity in order to be at the optimal tip speed ratio for each machine.

\section{Conclusion}

Several advantages of CFWT, compared with AFWT, have been highlighted. Among them, the main are listed below:

(i) the CFWT are insensitive to the inflow direction;

(ii) the axial geometry of the elementary CFWT facilitate the conceiving of modular assembly of towers and cluster of towers;

(iii) towers and clusters allow to harness the current over the whole section and to control the impact onto these currents by working on the global architecture of the farm; (iv) towers and clusters facilitate the use of anchor and mooring and compatible with high depth exploitation.

Besides, it has been pointed out that the well-known weaknesses of Darrieus turbines for air applications are reduced or even collapses for water applications. First, helical and delta shapes of blades are designed to smooth out the cyclic hydrodynamic loadings. These shape allow at the same time the self-starting of the turbine. Then, it became apparent that the smaller efficiency of CFWT compared with AFWT for free fluid flow condition can be balanced within a careening effect obtained by a well thought farm architecture.

Concerning this last point, several simulations have been performed to evaluate quantitatively the increase of efficiency due to the use of towers and clusters of towers. It has been shown that the efficiency increases with the tower height and stabilizes near 8 CFWT. This case corresponds to an efficiency of $33 \%, 4 \%$ more that the isolated 3D CFWT. The 2D asymptotic tower gives $34.85 \%$. Furthermore, the cluster of $2 \mathrm{D}$ facing towers separated by two turbine diameters presents an increase of efficiency that stabilizes near 10 CFWT. This case corresponds to an efficiency of $40.5 \%$, almost $6 \%$ more than the $2 \mathrm{D}$ isolated tower and $11.5 \%$ more than the $3 \mathrm{D}$ isolated CFWT.

Obviously, increasing the efficiency of CFWT clusters decreases the tidal energy ressource downstream the system. This is probably not always desirable as it can have a significant environmental impact. However, in some tidal potential site of limited expanse, we might be able to harvest the most energy with the smallest implantation surface. In addition, more efficient converter systems lead to less machines, less structure and less cost for the same power output. This is why, rising the efficiency of CFWT clusters seems to be an important goal. 


\section{Acknowledgment}

The authors wish to thank EDF R\&D for its technical and financial support as part of the "Hydroliennes en mer" $\mathrm{R} \& \mathrm{D}$ program.

\section{References}

[1] Huang RX. Encyclopedia of energy, vol. 4. Amsterdam: Elsevier; 2004.

[2] Fraenkel P. Seagen: pioneering megawatt scale tidal stream power generation. In: Ocean energy international conference; 2006.

[3] Daviau JF, Majastre H, Guena F, Ruer J. Divers aspects de l'exploitation de l'énergie des courants marins. In: Sea Tech Week. Brest: France; 2004.

[4] Blue Energy Canada. (www.bluenergy.com); 2000.

[5] Gorlov AM. Helical turbines for the gulf stream: conceptual approach to design of a large-scale floating power farm. Mar Technol 1998;35(3):175-82.

[6] Ponte di Archimede. 〈www.pontediarchimede.com〉.

[7] Agren O, Berg M, Leijon M. A time-dependent potential flow theory for the aerodynamics of vertical axis turbines. J Appl Phys 2005; 97(2):1-12.

[8] Maître T, Achard J-L. Une source d'énergie renouvelable possible: Les hydrauliennes, Revue de l'Energie 2003; (Numro spcial 546): 315-9.

[9] Brochier G, Fraunié P, Béguier C, Paraschivoiu I. Water channel experiments of dynamic stall on darrieus wind turbines blades. J Propul 1986;2(5):445-9.

[10] Ploesteanu C. Etude hydrodynamique d'un type d'hydrolienne axe vertical pour les courants marins. PhD thesis, Institut National Polytechnique de Grenoble, Grenoble, France; 2004.

[11] Amet E, Pellone C, Maître T, Achard J-L. Lacher tourbillonaire à l'arriére des pales d'une turbine darrieus. In: Conférence Française de Mécanique. Grenoble: France; 2007.

[12] Betz A. Wind-energie und ihre ausnutzung durch windmhlen. Göttingen, Germany: Vandenhoek and Ruprecht; 1926.

[13] Garrett C, Cummins P. Generating power from tidal currents. J Waterw, Port, Coastal, Ocean Eng 2004:114-8.
[14] Templin RJ. Aerodynamics performance theory for the NCR vertical-axis wind turbine, N.A.E Report LTR-LA-160.

[15] Strickland JH, Webster BT, Nguyen T. A vortex model of the darrieus turbine: an analytical and experimental study. J Fluids Eng 1979;101:500-5.

[16] Paraschivoiu I. Wind turbine design. UK: Polytechnic International Press; 2002.

[17] Ponta FL, Jacovkis PM. A vortex model for Darrieus turbine using finite element techniques. Renewable Energy 2001;24:1-18.

[18] Takamatsu Y, Furukawa A, Okuma K, Shimogama Y. Study on hydrodynamic performance of Darrieus-type cross-flow turbine. Bull JSME 28: 240

[19] Zori LAJ, Rajagopalan RG. Navier-Stokes calculation of rotor-airframe interaction in forward flight. J Am Helicopter Soc 40.

[20] Sheldhal RE, Blackwell BF, Feltz LV. Wind tunnel performance data for the Darrieus wind turbine with NACA 0012 blades. Technical Report SAND76-0130, SANDIA Laboratories; March 1977.

[21] Sheldhal RE, Klimas PC. Aerodynamic characteristics of seven symmetrical airfoil sections through 180-degree angle of attack for use in aerodynamic analysis of vertical axis wind turbines. Technical Report SAND80-2114, SANDIA Laboratories; March 1981.

[22] Laneville A, Vittecoq P. Dynamic stall: the case of the vertical axis wind turbine. J Sol Energy Eng 1986;108:140-5.

[23] Fraunié P, Beguier C, Paraschivoiu I. Importance du décrochage dynamique dans les calculs aérodynamiques du rotor darrieus. J de Mécanique Théorique et appliquée 1985;4(6):785-804.

[24] Shiono M, Suzuki K, Kiho S. An experimental study of the characteristics of a Darrieus turbine for tidal power generation. Electr Eng Jpn 2000;132(3):315-9.

[25] Van Bussel GJW. The development of turby, a small vawt for the built environment. In: Global wind energy conference. Delpht: The Netherlands; 2004.

[26] Faure TD, Pratte BD, Swan DH. The Darrieus hydraulic turbinemodel and field experiments. In: 4th ASME international symposium for hydro power and fluid machinery, San Francisco; 1986.

[27] Ponta F, Dutt GS. An improved vertical-axis water-current turbine incorporating a channelling device. Renewable Energy 2000;20: 223-41. 